\title{
RESENHA
}

\section{ENTRE O PATRIMÔNIO MATERIAL E IMATERIAL: OS MUSEUS PEDAGÓGICOS E OS VESTÍGIOS DA CULTURA ESCOLAR ESPANHOLA}

DOI: http://dx.doi.org/10.1590/2236-3459/76412

Karla Simone Willemann Schütz

Universidade do Estado de Santa Catarina (Udesc), Florianópolis/Santa Catarina, Brasil

ÁLVAREZ DOMínGUEZ, Pablo. Los Museos Pedagógicos en España: Entre la memoria y la creatividad. Sevilha: Editorial Universidad de Sevilla, 2016.

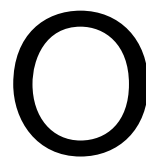

espaço escolar é também um local de produção de cultura, cultura esta que toma forma por meio dos processos formativos que nesse espaço se desenrolam. Tais processos, por sua vez, estão materializados nos locais, objetos e outros documentos que fazem parte do patrimônio cultural da escola. Emergindo de uma cultura compartilhada, este patrimônio se relaciona a modos de fazer e modos de sociabilidade vivenciados nas diversas instituições e ambientes de ensino. A partir deste entendimento o historiador da educação Escolano Benito (2012) considera que é necessário que esse "bem comum", por ele denominado "patrimônio educativo", seja um objeto de preocupação e preservação. Pois o patrimônio educativo está tanto associado à formação da identidade social dos indivíduos quanto relacionado à base da formação escolar individual. Nesse sentido, Escolano Benito reforça ainda que estes "bens comuns" também podem ser considerados objetos estratégicos no entendimento do passado e presente da História da Educação, pois possibilitam a valorização de bens que em outras temporalidades foram "subestimados", mas que agora podem ser observados a partir de novos olhares. Aparecendo como indícios visíveis do passado, os vestígios materiais da 
História da Educação podem ser considerados - a partir destes "novos olhares" testemunhas de experiências e indiciadores de práticas, bem como componentes identitários de uma memória acerca da escolarização.

Como afirma o antropólogo Daniel Miller (2013), as evidências materiais também se referem ao imaterial. Nesse sentido, o interesse pelo estudo dos "trecos" e "coisas", pela cultura material, é tanto no que diz respeito à maneira como "pessoas fazem coisas", quanto à maneira como "as coisas fazem as pessoas". Portanto, estas duas dimensões (material e imaterial) não devem ser pensadas como diametralmente distintas ou antagônicas, mas como elementos que estabelecem uma relação de troca e complementaridade. Os objetos, documentos, práticas, relações e memórias que podem ser entrevistos no espaço escolar - mas também em outros lugares fora dele -, logo, se entrecruzam na formação do que entendemos como cultura escolar.

Percebe-se que é adotando estas perspectivas acima aludidas que Pablo Álvarez Domínguez organiza a obra Los Museos Pedagógicos en España: Entre la memoria y la creatividad, lançada em 2016 na Espanha pela editora da Universidade de Sevilha. Como professor de Teoria e História da Educação na Faculdade de Ciências da Educação na Universidade de Sevilha (Espanha), Álvarez Domínguez realiza pesquisas relacionadas à História da Educação e sua Didática, à recuperação do patrimônio educativo, à museologia da educação e à pedagogia museística, questões candentes e que norteiam do início ao fim as páginas da publicação aqui referida. Los Museos Pedagógicos en España conta com a participação, na produção dos capítulos, de 27 profissionais ligados a instituições de ensino superior e a museus pedagógicos e da História da Educação estabelecidos nas diversas regiões do território espanhol. A maioria destes autores exercem (ou exerceram) prática docente junto a universidades espanholas e tem como temática principal de suas pesquisas a História da Educação. Como exceção, aparecem apenas 5 autores que, por sua vez, estão vinculados a alguns desses museus, realizando funções de gestão ou técnicas.

Já na apresentação do livro, o trabalho com o patrimônio educativo, entendido como marca do passado, é proposto a partir de caminhos renovados no que se refere à metodologia, à temática e à documentação. Apresentando a diversidade espanhola de projetos de conservação, de exibição e pesquisa, a principal motivação do autor se apresenta: a vontade de dar a conhecer estes espaços, de demonstrar que o patrimônio educativo é fonte relevante para o conhecimento e compreensão do passado. Nesse sentido, o livro envereda por estradas que perpassam das escolas-museu aos museus virtuais.

Ao longo do livro são apresentados tanto passado e presente quanto as perspectivas de futuro desses espaços: cada um dos capítulos traz um pequeno histórico da instituição ou museu a que se refere, comenta sobre os projetos e as situações atuais de seus acervos, assim como expressa algumas propostas para o futuro destes locais, mostrando outras abordagens possíveis. São, assim, 17 capítulos que trazem à tona diversas experiências museísticas espanholas e que, por sua vez, se propõem a servir de referência e indicar a outros pesquisadores espanhóis - e também, por que não, de outros lugares do mundo - modelos a respeito das pesquisas e espaços onde um dos principais intuitos é a preservação de parte do patrimônio educativo espanhol. Como resultado advindo dos esforços da Sociedad Española para el Estudio del Patrimonio Historico 
Educativo (SEPHE), sociedade da qual Álvarez Domínguez é integrante, a obra aponta um debate profícuo na qual se mesclam memória e criatividade, tanto na apresentação dos espaços onde está salvaguardado este patrimônio educativo quanto nas inúmeras pesquisas realizadas nestes locais, mas também acerca deles.

Mas, por que falar de museus de pedagogia, educação e ensino? No primeiro dos capítulos, de autoria do próprio organizador do livro, esta pergunta parece ser colocada com o objetivo de assinalar os pressupostos que regeram a produção da publicação, entre elas destacar as novas possibilidades que se abrem no campo dos estudos históricoeducativos. No livro, o organizador destaca a exploração de uma dimensão etnográfica entendida em seu sentido amplo - no estabelecimento de estudos nestes espaços museísticos. Tal mirada etnográfica, segundo Álvarez Domínguez, abordaria interpretações mais complexas e críticas acerca da cultura escolar, dos museus e das relações que podem ser estabelecidas entre esses aspectos. Tal aproximação, baseada numa descrição densa, principalmente dos objetos da cultura material escolar presentes nestes espaços, poderia dar conta de significados e significações possivelmente ainda não observados e presentes em determinadas práticas e pensamentos da cultura escolar.

Dentro da gama de espaços selecionados por Álvarez Domínguez para integrar o livro, podem ser encontrados museus e instituições com trajetórias reconhecidas, mas também outros que por conta de sua existência ainda prematura ainda não têm tamanha projeção pública. Há também espaços já perfeitamente organizados e outros que ainda se esforçam para atingir tal organização, ou ainda aqueles que dispõem de coleções com objetos raros ou que conseguiram arrecadar número considerável de recursos financeiros. No entanto, muitos ainda lutam para conseguir apoio financeiro a fim de alcançar um número suficiente de profissionais para seu funcionamento, além de aumentar a divulgação, o público e as atividades que a eles poderiam ser oferecidas. Tais aspectos parecem estar favorecidos naqueles espaços vinculados à rede de museus do Estado espanhol, embora ainda sejam uma realidade distante de outros ambientes.

Entretanto, apesar de suas particularidades, todos esses locais apresentados ao longo do livro se colocam como espaços sociais dinâmicos de aprendizagem e conhecimento, aptos à "interlocução" entre gerações acerca da cultura histórico-educativa, inclusive pela sua inserção no mundo virtual. Muitos destes museus possuem páginas na internet, por exemplo, um recurso significativo na busca por inovação e por este diálogo entre passado, presente e, por que não, futuro. Pois como mesmo afirma o organizador da obra, a emergência da museologia da educação na História da Educação se coloca como uma das linhas de investigação mais inovadoras e frutíferas que vêm sendo desenvolvidas no meio da comunidade de historiadores da educação nos últimos 20 anos. Nesse cenário, o papel desempenhado pelo museu de educação seria refletir acerca de uma História da Educação que seja capaz de se mover entre a memória e a criatividade, entre passado e inovação.

Sendo assim, os museus pedagógicos congregariam uma função cultural e educativa, constituindo-se em espaços de convivência, entretenimento e socialização que possibilitam alavancar a valorização do papel desempenhado pela educação ao longo do tempo. Busca-se assim promover o conhecimento histórico-educativo em particular, mas entendendo que este não pode ser desvinculado de nossa cultura em geral. Nas palavras de Álvarez Domínguez (2016, p. 30): 
Somos conscientes de que el patrimonio histórico-educativo se comunica, se aprende, se interioriza, se vive y se siente. Lo necesitamos para saber quiénes somos, para saber qué somos y, sobre todo, para no cegarnos en lo que queremos y en lo que podemos llegar a ser.

Enfim, mediante o conteúdo exposto ao longo da obra é possível compreender que a partir dos patrimônios material e imaterial da História da Educação presentes nos museus e instituições pode-se valorizar, mas também pesquisar, as memórias que tangenciam estas culturas escolares, não meramente atendendo a fins de celebração ou preservação, mas sim buscando compreender os significados desses patrimônios material e imaterial educativos no presente e quais os questionamentos que a eles podem ser colocados a fim de entendermos a contemporaneidade. Estes espaços possibilitam, ainda, inquirir sobre os diversos processos históricos que promoveram transformações no referencial simbólico presente nessas materialidades e imaterialidades e que emergiram de uma atuação mútua entre a cultura da sociedade e a cultura escolar.

\section{Referências}

ESCOLANO BENITO, Augustín. Las materialidades de la escuela (a modo de prefacio). In: SILVA, Vera Lúcia Gaspar da; PETRY, Marília Gabriela (Orgs.). Objetos da Escola: espaços e lugares de constituição de uma cultura material escolar (Santa Catarina séculos XIX e XX). Florianópolis: Insular, 2012. p. 11-18.

MILLER, Daniel. Teoria das coisas. In: Trecos, troços e coisas: estudos antropológicos sobre a cultura material. Rio de Janeiro: Zahar, 2013. p. 66-118.

KARLA SIMONE WILLEMANN SCHÜTZ possui graduação (licenciatura e bacharelado) em História (2013) e Mestrado (2015) pela Universidade do Estado de Santa Catarina (Udesc). Atualmente é Doutoranda no Programa de Pós-Graduação em História (Udesc) e participante do Grupo de Pesquisa Culturas Escolares, História e Tempo Presente (Cehtp) e do Grupo de Estudos História, Cultura Escrita e Leitura (Gehcel) vinculados ao Laboratório de Patrimônio Cultural (LapPac - Udesc).

Endereço: Rua Desembargador Pedro Silva, 2202 - 88070-700 - Florianópolis/SC - Brasil.

E-mail: karlawschutz@gmail.com

Recebido em 11 de setembro de 2017.

Aceito em 22 de setembro de 2017. 